\title{
Repair of Coronary Artery Perforation Into the Left Ventricle Using Graftmaster Stent Graft After Complicated Percutaneous Coronary Intervention of Myocardial Bridge
}

\author{
Waleed Alia, b, Santhosh R. Devarapallya, Satyanarayana R. Vaidya ${ }^{a}$
}

\begin{abstract}
A myocardial bridge (MB) is a band of heart muscle that lies on the top of a coronary artery, instead of underneath it. This leads to tunneling of coronary artery through this segment of the myocardium which can be mechanically compressed during systole, also known as myocardial bridging. Although usually asymptomatic, it can be associated with exertional angina, acute coronary syndrome, cardiac arrhythmia or even sudden cardiac death. The utilization of percutaneous coronary intervention (PCI) of the bridged segment to ameliorate vessel compression and normalize blood flow is limited due to concerns of complications, particularly restenosis and perforation. Although conventional management of coronary perforation includes prolonged balloon dilation and reversal of anticoagulation, stent grafting of these perforations is not uncommonly utilized. We report a case of a patient with symptomatic MB who underwent a PCI of the bridging segment of the left anterior descending (LAD) coronary arterywhich was complicated with a perforation into the left ventricle. As patient became symptomatic, the perforation was emergently repaired using a Graftmaster ${ }^{\circledR}$ RX coronary stent graft system (Abbott Vascular) with complete alleviation of symptoms and successful radiographic resolution.
\end{abstract}

Keywords: Coronary artery perforation; Myocardial bridge; Graft stent; Left ventricle

\section{Introduction}

First introduced by Reyman in 1737 [1], myocardial bridge (MB) is an abnormal segment of a coronary artery with an intramuscular course. This bridge compresses the tunneled segment during systole, which remains clinically silent in most cases [2, $3]$. Although usually asymptomatic in the majority of patients,

\section{Manuscript accepted for publication February 02, 2017}

aDepartment of Medicine-Cardiology, Cape Fear Valley Medical Center, Fayetteville, NC, USA

${ }^{\mathrm{b} C}$ Corresponding Author: Waleed Ali, Department of Medicine-Cardiology, Cape Fear Valley Medical Center, 1638 Owen Drive, Fayetteville, NC 28304, USA. Email: waleeed197897@yahoo.com

doi: https://doi.org/10.14740/jmc2750w symptomatic patients often require treatment [2-4]. We report a case of a patient with $\mathrm{MB}$ with refractory angina despite medical management. After the patient refused surgical intervention, a percutaneous coronary intervention (PCI) was performed which was complicated with a perforation that was managed successfully with the help of a Graftmaster coronary stent graft.

\section{Case Report}

A 52-year-old Caucasian male presented to our facility complaining of a sudden onset of substernal chest pain, described as heaviness with radiation to his left shoulder and arm. Past medical history was significant for hypertension and hypercholesterolemia. Patient had a 20 pack-year smoking history. He denied alcohol or recreational drugs. Family history was unremarkable. On physical exam, he was afebrile with a blood pressure of $119 / 83 \mathrm{~mm} \mathrm{Hg}$, pulse rate of $80 / \mathrm{min}$ and a respiratory rate of $18 / \mathrm{min}$. Complete blood count and basic metabolic panel were unremarkable. Initial troponin value was $0.369 \mathrm{ng} / \mathrm{mL}$ which peaked at $0.630 \mathrm{ng} / \mathrm{mL}$. There were no acute ischemic signs on electrocardiogram. Two-dimensional echocardiogram showed a normal left ventricular ejection fraction with no wall motion abnormalities. Cardiac catheterization was performed which revealed a patent left circumflex artery and a patent dominant right coronary artery, $50 \%$ ostial lesion of the left anterior descending (LAD) coronary artery and severe myocardial bridging of the mid-LAD with near total occlusion during systole (Fig. 1). After discussion with the patient, he was discharged on medical management with antianginals. Patient persisted to experience exertional chest pain during follow-up in the next 6 months. In light of the refractory nature of his symptoms, he was advised a surgical intervention which he refused. Hence, he was scheduled for a PCI.

Intravascular ultrasound revealed a minimal luminal area of the ostial LAD at $4.4 \mathrm{~mm}^{2}$ and mid LAD at the bridging segment at $3.9 \mathrm{~mm}^{2}$. A $2.5 \times 12 \mathrm{~mm}$ Emerge balloon was placed across the myocardial bridging segment and inflated up to 6 atm for $15 \mathrm{~s}$, thereafter, a $3 \times 20 \mathrm{~mm}$ Promus Promier stent was placed across the mid-LAD and deployed at $11 \mathrm{~atm}$ for $15 \mathrm{~s}$ resulting in resolution of myocardial bridging and a significant improvement of the distal flow (Fig. 2). Post-stenting dilation was carried out up to $19 \mathrm{~atm}$ for $10 \mathrm{~s}$. The patient immediately started complaining of chest pain after the dilation. Post-in- 

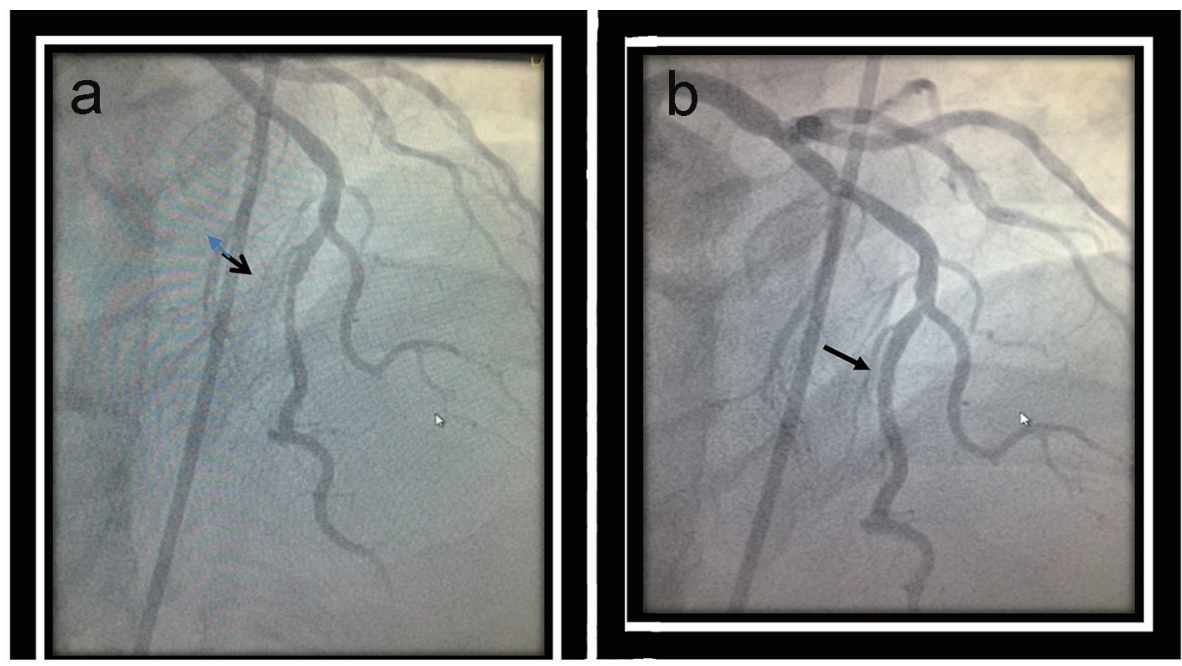

Figure 1. Dynamic compression of the tunneled segment of the mid left anterior descending (LAD) coronary artery during systole (a) with complete reverse during diastole (b).
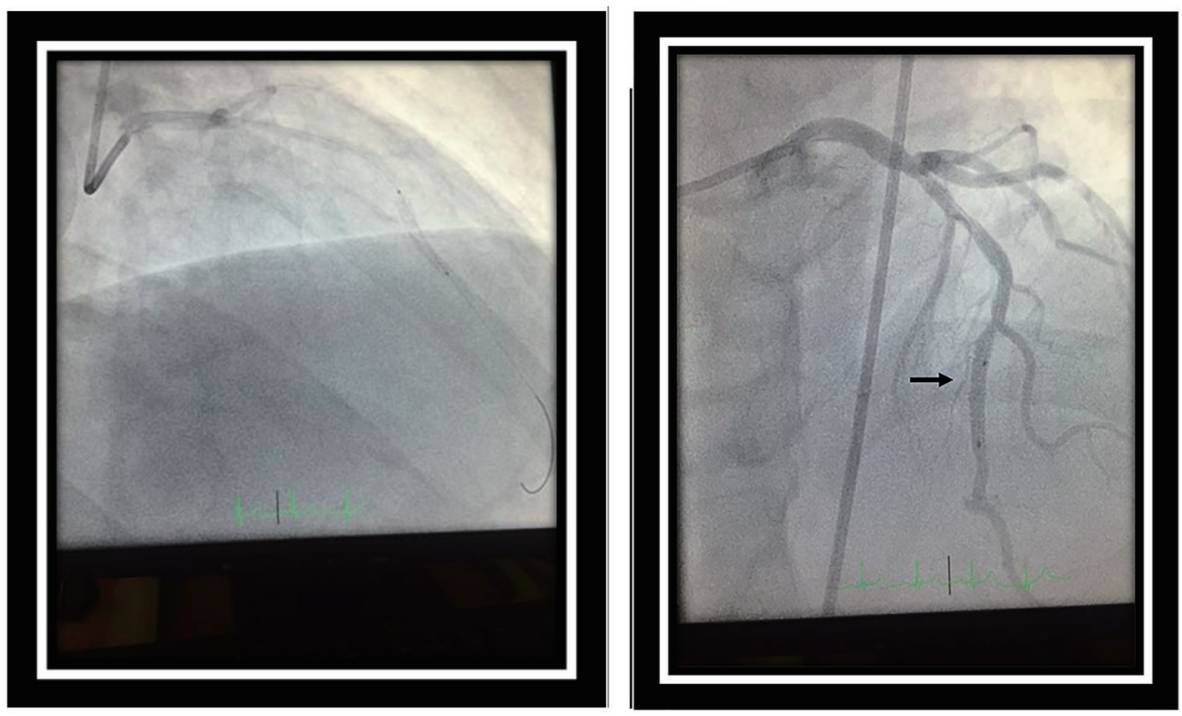

Figure 2. Deployment of $3 \times 20 \mathrm{~mm}$ Promus Promier stent in the tunneled segment of the mid-left anterior descending (LAD) coronary artery with resolution of the myocardial bridge (black arrow).

tervention angiogram revealed a focal free perforation in the distal part of the stented segment with extravasation of contrast freely into the left ventricular cavity (Fig. 3). A decision was made to immediately stent the perforation with a $2.8 \times 16 \mathrm{~mm}$ Graftmaster coronary stent graft. Post-stent dilatation was carried out up to $19 \mathrm{~atm}$ for $10 \mathrm{~s}$. Left coronary angiography after the deployment of the stent graft confirmed a successful repair of the perforation with an absence of contrast leak (Fig. 4). Chest pain resolved over the next $30 \mathrm{~min}$ and the patient was symptom free at 1-month and 6-month follow-ups.

\section{Discussion}

The prevalence of the MB has been reported to be $0.5-16 \%$ af- ter coronary angiography while up to $50 \%$ following autopsy in one study [5] arguing for possible many undetected cases of MB during angiography. Nevertheless, computed tomography (CT) angiography showed superiority over angiography in revealing this anomaly. In a recent study, Teofilovski et al examined 96 cadaver hearts from adult individuals of both genders in Serbia, and it was found that MB is not rare in the examined sample and often associated with other congenital anomalies [6]. Affected individuals are usually asymptomatic. Symptomatic presentations can range from exertional angina to rare acute coronary syndrome or even sudden death due to arrhythmias [7]. Conservative medical management using antianginals is the initial preferred approach with special consideration to avoid nitroglycerin as it may aggravate the symptoms by intensifying the systolic compression of the bridged 


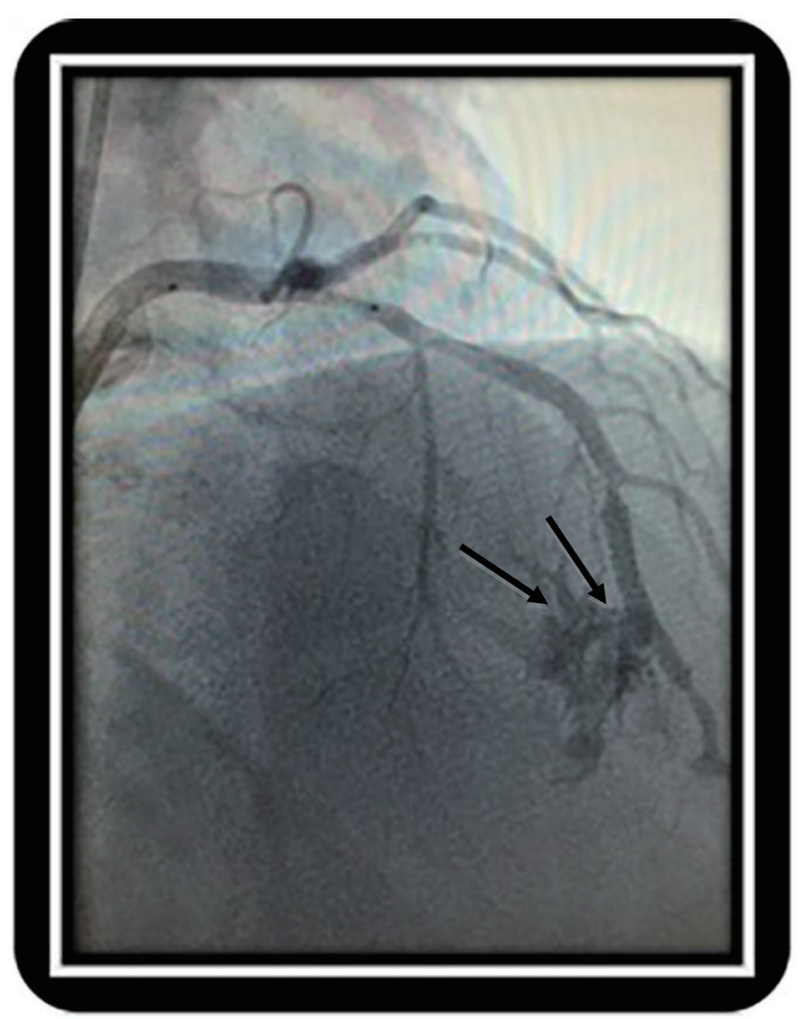

Figure 3. Post-intervention angiogram revealed a focal free perforation in the distal part of the stented segment with contrast entering into the left ventricular cavity.

segment and enhances the retrograde flow in the proximal segments $[8,9]$. However, in refractory cases, a percutaneous or surgical approach may be required. Interventional cardiologists are often apprehensive about a percutaneous approach due to high restenosis arte $[10,11]$ besides the risk of potential

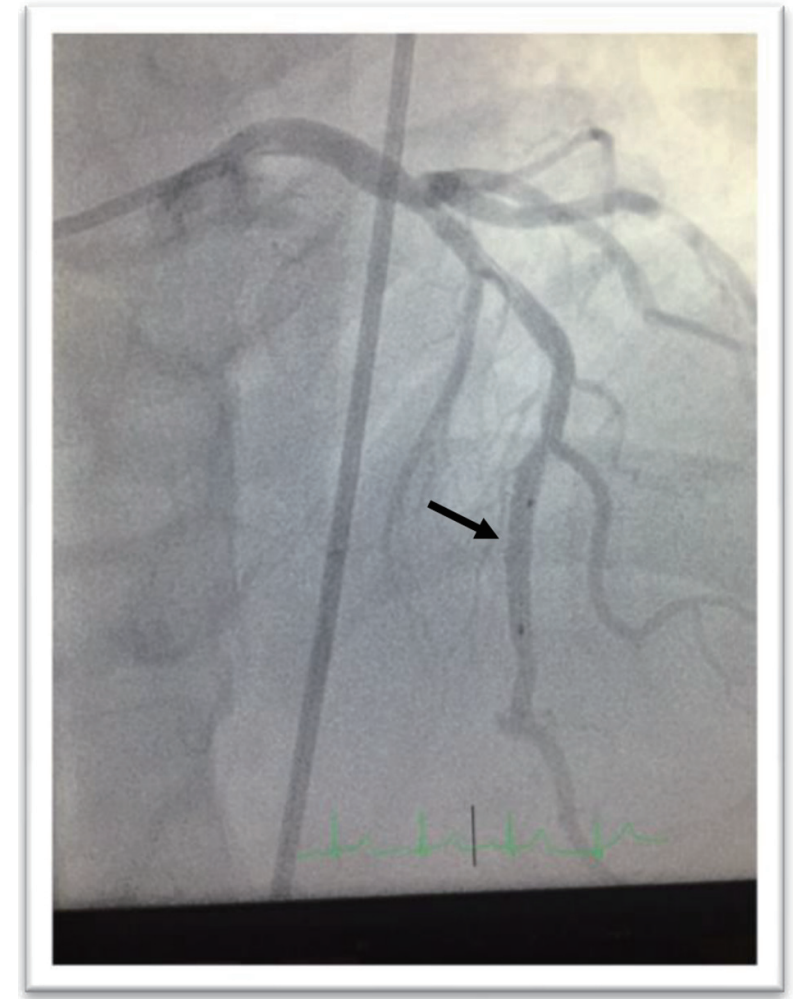

Figure 4. Left coronary angiography after deployment of the stent graft confirmed a successful repair of perforation with an absence of extravasation of contrast from the coronary artery.

life-threatening perforation which can be tricky to manage. The implement of the intravascular ultrasound helps to scrutinize the coronary anatomy and carefully select the appropriate balloon size to avoid the perforation risk to some extent [12]. Traditionally, when perforations do occur, prolonged

Table 1. All Reported Cases of Myocardial Bridge Perforation After Coronary Artery Intervention Since 1997 to the Present

\begin{tabular}{lllllll}
\hline Author & Year & Patient demographic & $\begin{array}{l}\text { Target } \\
\text { coronary } \\
\text { artery }\end{array}$ & $\begin{array}{l}\text { Complication/ } \\
\text { perforation }\end{array}$ & Rescue & $\begin{array}{l}\text { IVUS before } \\
\text { stenting }\end{array}$ \\
\hline Hering et al [15] & 1997 & 47 years, male & LAD & Fistula to RV & Closed spontaneously & No \\
\hline Berry et al [18] & 2002 & 67 years, female & LAD & To the pericardium & Balloon inflation to CABG & No \\
\hline Demin [20] & 2003 & Not reported & LAD & To the pericardium & PTFE covered stent & No \\
\hline Li et al [3] & 2008 & 44 years, male & LAD & To the pericardium & Balloon stent & No \\
Li et al [3] & 2008 & 54 years, female & LAD & To the pericardium & $\begin{array}{l}\text { CABG after failure of stent } \\
\text { balloon }\end{array}$ & No \\
\hline Shen et al [2] & 2009 & 75 years, female & LAD & Cavity spilling & PTFE-covered stent & Unknown \\
\hline Zhang et al [14] & 2010 & 46 years, female & LAD & To the pericardium & PTFE-covered stent & Yes after perforation \\
Tomasevic et al [19] & 2011 & 36 years, male & LAD & Fistula to RV & PTFE-covered stent & No \\
\hline Ernst et al [13] & 2013 & Not mentioned & LAD & To the pericardium & Graftmaster stent graft & No \\
\hline Ekici et al [17] & 2014 & 74 years, male & LAD & To the pericardium & Balloon stent & No \\
Becher et al [16] & 2015 & 75 years, not mentioned & LAD & Fistula to RV & PTFE-covered stent & Unknown \\
\hline
\end{tabular}

Intravascular ultrasound (IVUS) before stent implantation was not clearly mentioned in some studies. 
balloon dilation proximal to the site of perforation to prevent tamponade is the preferred approach, along with reversal of anticoagulation. However, with improving stent prosthesis, management of these perforations has been shown feasible with the help of covered stents. In our case, we successfully repaired the perforation with the help of Graftmaster coronary stent graft system (Abbott Vascular). The Graftmaster stent graft is indicated in repair of coronary artery perforation and is contraindicated in cases where treatment area is limited to allow full balloon dilation or placement of the stent graft. Previous cases have reported perforation of the bridged segment of coronary artery into the right ventricle and the pericardial space (Table 1 [2, 3, 13-20]). We here report the first case of perforation of a tunneled coronary artery into the left ventricle. A repair of perforation was performed using a stent graft with good results.

\section{Conclusion}

$\mathrm{MB}$ is not a rare anomaly as we used to think. Symptomatic myocardial bridging can often be refractory to medical management requiring intervention. Perforation is a rare complication if the bridged segment is percutaneously intervened and yet can be successfully repaired using a stent graft.

\section{Conflicts of Interest}

None.

\section{References}

1. Reyman HC. Disertatis de vasis cordis propiis. Bibl Anat. 1737;2:366.

2. Shen TY, Chen CC, Tseng YZ. Stent graft used to rescue coronary rupture during percutaneous coronary intervention for myocardial bridge. Intern Med. 2009;48(12):993996.

3. Li W, Li Y, Sheng L, Gong Y. Myocardial bridge: is the risk of perforation increased? Can J Cardiol. 2008;24(11):e8081.

4. Kurtoglu N, Mutlu B, Soydinc S, Tanalp C, Izgi A, Dagdelen S, Bakkal RB, et al. Normalization of coronary fractional flow reserve with successful intracoronary stent placement to a myocardial bridge. J Interv Cardiol. 2004;17(1):33-36.

5. Ishikawa Y, Akasaka Y, Suzuki K, Fujiwara M, Ogawa T, Yamazaki K, Niino H, et al. Anatomic properties of myocardial bridge predisposing to myocardial infarction. Circulation. 2009;120(5):376-383.

6. Teofilovski-Parapid G, Jankovic R, Kanjuh V, Virmani R, Danchin N, Prates N, Simic DV, et al. Myocardial bridges, neither rare nor isolated-Autopsy study. Ann Anat. 2016;210:25-31.
7. Lee MS, Chen CH. Myocardial Bridging: An Up-to-Date Review. J Invasive Cardiol. 2015;27(11):521-528.

8. Ge J, Jeremias A, Rupp A, Abels M, Baumgart D, Liu F, Haude $\mathrm{M}$, et al. New signs characteristic of myocardial bridging demonstrated by intracoronary ultrasound and Doppler. Eur Heart J. 1999;20(23):1707-1716.

9. Hongo $\mathrm{Y}$, Tada H, Ito K, Yasumura Y, Miyatake K, Yamagishi M. Augmentation of vessel squeezing at coronary-myocardial bridge by nitroglycerin: study by quantitative coronary angiography and intravascular ultrasound. Am Heart J. 1999;138(2 Pt 1):345-350.

10. Mohlenkamp S, Hort W, Ge J, Erbel R. Update on myocardial bridging. Circulation. 2002;106(20):2616-2622.

11. Haager PK, Schwarz ER, vom Dahl J, Klues HG, Reffelmann T, Hanrath P. Long term angiographic and clinical follow up in patients with stent implantation for symptomatic myocardial bridging. Heart. 2000;84(4):403-408.

12. Ge J, Erbel R, Rupprecht HJ, Koch L, Kearney P, Gorge $\mathrm{G}$, Haude M, et al. Comparison of intravascular ultrasound and angiography in the assessment of myocardial bridging. Circulation. 1994;89(4):1725-1732.

13. Ernst A, Bulum J, Separovic Hanzevacki J, Lovric Bencic M, Strozzi M. Five-year angiographic and clinical follow-up of patients with drug-eluting stent implantation for symptomatic myocardial bridging in absence of coronary atherosclerotic disease. J Invasive Cardiol. 2013;25(11):586-592.

14. Zhang M, Kang WC, Moon CI, Han SH, Ahn TH, Shin EK. Coronary artery perforation following implantation of a drug-eluting stent rescued by deployment of a covered stent in symptomatic myocardial bridging. Korean Circ J. 2010;40(3):148-151.

15. Hering D, Horstkotte D, Schwimmbeck P, Piper C, Bilger J, Schultheiss HP. [Acute myocardial infarct caused by a muscle bridge of the anterior interventricular ramus: complicated course with vascular perforation after stent implantation]. Z Kardiol. 1997;86(8):630-638.

16. Becher T, Baumann S, Huseynov A, Behnes M, Borggrefe $\mathrm{M}$, Akin I. Coronary artery perforation in a patient with STEMI and a myocardial bridge: an increased risk for coronary artery perforation? Cardiovasc Revasc Med. 2015;16(4):246-248.

17. Ekici B, Erkan AF, Kutuk U, Tore HF. Successful management of coronary artery rupture with stent-graft: a case report. Case Rep Med. 2014;2014:391843.

18. Berry JF, von Mering GO, Schmalfuss C, Hill JA, Kerensky RA. Systolic compression of the left anterior descending coronary artery: a case series, review of the literature, and therapeutic options including stenting. Catheter Cardiovasc Interv. 2002;56(1):58-63.

19. Tomasevic M, Dikic M, Ostojic M. Stenting a myocardial bridge: a wrong decision in STEMI? Acta Cardiol. 2011;66(1):89-91.

20. Demin VV. [Successful correction with stent-graft of coronary artery rupture after angioplasty]. Angiol Sosud Khir. 2003;9(2):118-121. 